\title{
Flos Albiziae aqueous extract and its active constituent quercetin potentiate the hypnotic effect of pentobarbital via the serotonergic system
}

\author{
MENG-FEI YE ${ }^{1}$, ZHENG LIU ${ }^{1,2}$, SHU-FANG LOU ${ }^{1}$, ZHEN-YONG CHEN $^{1}$, AI-YUE YU $^{3}$, \\ CHUN-YAN LIU ${ }^{4}$, CHAO-YANG YU ${ }^{1}$, HUA-FANG ZHANG ${ }^{1}$ and JIAN ZHANG ${ }^{1}$ \\ ${ }^{1}$ Department of Basic Medicine, Medical College of Shaoxing University; ${ }^{2}$ Laboratory of Forensic Toxicology, \\ Judicial Identification Center of Shaoxing University; ${ }^{3}$ Department of Basic Course, Shaoxing University Yuanpei College; \\ ${ }^{4}$ Department of Orthopedics, Shaoxing People's Hospital, Shaoxing, Zhejiang 312000, P.R. China
}

Received July 20,2015; Accepted August 26, 2015

DOI: 10.3892/br.2015.518

\begin{abstract}
Flos albiziae (FA) is reportedly used for treatment of insomnia and anxiety in traditional medicine. The hypnotic effect of an extract of FA (FAE) and its constituent quercetin [2-(3,4-dihydroxyphenyl)-3,5,7-trihydroxy-4H-chromen-4-one, $\mathrm{QR}]$ was examined in mice. QR is a widely distributed natural flavonoid abundant in FA flowers and other tissues. The possible mechanisms underlying the hypnotic effects of FAE and QR were investigated using behavioral pharmacology. FAE and QR significantly potentiated pentobarbital-induced [50 $\mathrm{mg} / \mathrm{kg}$, intraperitoneal (ip)] sleep (prolonged sleeping time; shortened sleep latency) in a dose-dependent manner, and these effects were augmented by administration of 5-hydroxytryptophan (5-HTP), a precursor of 5-hydroxytryptamine. With a sub-hypnotic dose of pentobarbital $(28 \mathrm{mg} / \mathrm{kg}$, ip), FAE and QR significantly increased the rate of sleep onset and were synergistic with 5-HTP (2.5 $\mathrm{mg} / \mathrm{kg}$, ip). Pretreatment with $p$-chlorophenylalanine, an inhibitor of tryptophan hydroxylase, significantly decreased sleeping time and prolonged sleep latency in pentobarbital-treated mice, whereas FAE and QR significantly reversed this effect. Data show that FAE and QR have hypnotic activity, possibly mediated by the serotonergic system. The present study offers a rationale for the use of FA in treating sleep disorders associated with serotonin system dysfunction.
\end{abstract}

\section{Introduction}

Benzodiazepines are extensively used to treat insomnia; however, their uses are limited by concerns regarding long-term efficacy and the potential for abuse, dependence and adverse effects.

Correspondence to: Dr Zheng Liu, Department of Basic Medicine, Medical College of Shaoxing University, 900 Road of South City, Shaoxing, Zhejiang 312000, P.R. China

E-mail: liuzheng1212@163.com

Key words: quercetin, hypnotic, serotonergic system
Thus, complementary and alternative medicine is often a source for treating insomnia. Chinese herbal medicine (CHM), a form of complementary and alternative medicine, is often explored for treating insomnia, either with single herbs or with herbal formulas. Recently, $>200$ studies of CHM for insomnia from a systematic review indicated that CHM was similar to Western medication for treating insomnia, and that the frequency of adverse events associated with CHM were similar to that of the placebo; however, they were less frequent than that of Western medication (1). Therefore, identifying a single herb or herbal formula from CHM to treat insomnia is advantageous.

Albizia julibrissin Durazz is a small tree with smooth, gray-brown bark and doubly pinnate leaves. Clusters of pink flower heads are borne in summer (2) and the tree is widely distributed throughout Korea, China, Japan and Africa. The main active ingredients of the flowers include triterpenoids and their glycosides, flavonoids, alkaloids, organic acids, sterols, lignans and tannin. Quercetin [2-(3,4-dihydroxyphenyl)-3,5,7-trihydroxy-4H-chromen-4-one, QR] is a major constituent of the flowers of Flos albiziae (FA) and QR is identified in vegetables, fruits, red wine and other herbal preparations. Pharmacological research on aqueous extracts of FA (FAE) and QR indicate that they have broad bioactivity, such as antithrombotic and anti-inflammatory effects, anti-infectious and immunomodulatory activities (3), sedative and hypnotic effects (2), the ability to inhibit cancer cell proliferation and induce apoptosis $(4,5)$, antidepressant activity (6), and antioxidative and hypolipidemic properties (7-10). Certain studies have indicated that the antidepressant effects of FAE may be associated with increased plasma serotonin [5-hydroxytryptamine (5-HT)], norepinephrine and dopamine via inhibition of uptake (11), indicating that FAE or QR may have functions at the level of the central nervous system and monoamine neurotransmitters.

Serotonin, an important monoamine neurotransmitter in the brain, is reported to have a role in the modulation of sleep. The serotonergic system is necessary for sleep onset and maintenance, and the administration of the 5-HT synthesis inhibitor $p$-chlorophenylalanine (PCPA) induces insomnia that is selectively antagonized/reversed by the 5-HT precursor 5-hydroxytryptophan (5-HTP) (12). Studies indicate that 
certain single CHM herbs or extracts may potentiate sleep induced by pentobarbital via the serotonergic system $(13,14)$. In addition, it has been reported that anxiolytic-like effects of Albizia julibrissin may be mediated by changes of the serotonergic nervous system (15).

Thus, the hypothesis that FAE and QR may potentiate pentobarbital-induced sleep via the serotonergic system was explored in the present study. Mice were administered both compounds and changes in sleeping times and sleep latencies treated with hypnotic or sub-hypnotic doses of pentobarbital and 5-HTP and PCPA were measured to study the mechanism of the hypnotic effects of FAE and QR.

\section{Materials and methods}

Animals. Male ICR mice $(24 \pm 2 \mathrm{~g})$ were from Zhejiang University of Traditional Chinese Medicine (Zhejiang, China), and they were housed under controlled environmental conditions $\left(22 \pm 2^{\circ} \mathrm{C}\right.$, humidity $50 \pm 10 \%, 12 \mathrm{~h} \mathrm{light/dark} \mathrm{cycle,} \mathrm{lights}$ on at 8:00 a.m.) with ad libitum access to food and water. Mice were acclimated 1 week before testing and fasted for $12 \mathrm{~h}$ prior to the onset of the experiments. Experiments were carried out between 13:00 and 17:00 p.m. in a quiet room $\left(22-24^{\circ} \mathrm{C}\right)$. All procedures were conducted in accordance with the European Community guidelines for the use of experimental animals and approved by the Shaoxing University Committee on Animal Care and Use (Zhejiang, China).

Drugs and drug administration. Pentobarbital, 5-HTP, PCPA (Sigma-Aldrich, St. Louis, MO, USA), aqueous FAE, QR (Xi'an Kailai Biological Engineering Co., Ltd., Xi'an, China) and diazepam (DZ; $10 \mathrm{mg} / 2 \mathrm{ml}$; manufactured by People's Pharmaceutical Manufacturer, Tianjin, China) were used. For intragastric (ig) administration (10 ml/kg), FAE and DZ injection were dissolved in distilled water, and QR was suspended in $1 \%$ carboxymethyl-cellulose in physiological saline. For intraperitoneal (ip) injection $(10 \mathrm{ml} / \mathrm{kg}), 5$-HTP and pentobarbital were dissolved with physiological saline, and PCPA was suspended in $0.5 \%$ gum acacia/physiological saline. The hypnotic dose of pentobarbital (sleep onset $100 \%$ ) used was $50 \mathrm{mg} / \mathrm{kg}$, and $28 \mathrm{mg} / \mathrm{kg}$ was the sub-hypnotic dose (sleep onset $0 \%$ ). FAE, QR and DZ were administered (ig) $60 \mathrm{~min}$ prior to pentobarbital administration (ip). 5-HTP was injected (ip) 15 min prior to pentobarbital administration (ip). In a PCPA pretreatment test, mice received an injection of PCPA $(300 \mathrm{mg} / \mathrm{kg}$ between 12:00 a.m. and 13:00 p.m. for $24 \mathrm{~h}$ ) prior to the injection of pentobarbital.

Evaluation of sleep onset and sleeping time. The observers were blinded to the drug treatments. Following pentobarbital administration, each mouse was observed for sleep onset, as evidenced by rolling to their back and a loss of righting reflex for $>2 \mathrm{~min}$. This was considered to be sleeping. Mice that lost the righting reflex for $<2 \mathrm{~min}$ were considered to be awake. Sleep latency was recorded from pentobarbital injection to $1 \mathrm{~min}$ after the loss of the righting reflex. Sleep time was recorded from $1 \mathrm{~min}$ after the reflex loss to recovery of the righting reflex.

Data and statistical analysis. For statistical analysis, data were processed with Microsoft Excel and SPSS software
A

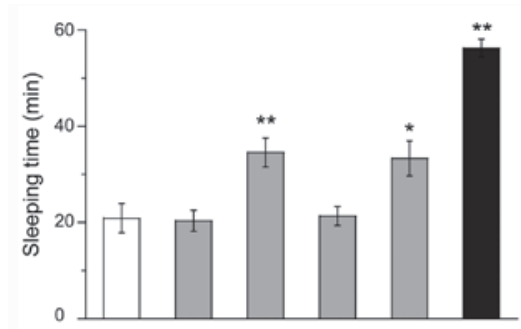

B

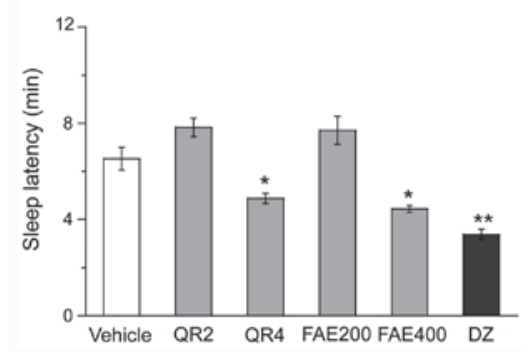

Figure 1. Effect of extract of Flos albiziae (FAE) and quercetin (QR) on the hypnotic response to pentobarbital-treated mice $(n=10)$. Mice dosed with pentobarbital $(50 \mathrm{mg} / \mathrm{kg}$, intraperitoneal) were provided vehicle $(10 \mathrm{ml} / \mathrm{kg})$, QR (2 or $4 \mathrm{mg} / \mathrm{kg}$ ), FAE (200 or $400 \mathrm{mg} / \mathrm{kg}$ ) and diazepam (DZ) (2 mg/kg), respectively. (A) Sleeping times and (B) sleep latencies were subsequently measured. Data are mean \pm standard deviation. Significant differences of DZ, FAE or QR-treated mice compared to the vehicle-treated mice $\left({ }^{*} \mathrm{P}<0.05\right.$ and $\left.{ }^{* *} \mathrm{P}<0.01\right)$.

(SPSS, Inc., Chicago, IL, USA). Values are mean \pm standard deviation for the indicated number of experimental animals. For statistical comparisons, data were analyzed by analysis of variance followed by the Students-Newman-Keuls test for post-hoc comparisons. For the sub-hypnotic pentobarbital dose test, a $\chi^{2}$ test was used to compare the number of mice that fell asleep. $\mathrm{P}<0.05$ was considered to indicate a statistically significant difference.

\section{Results}

Effect of FAE and QR on the onset and duration of sleep in pentobarbital-treated mice. FAE and QR had synergistic effects with pentobarbital. Mice treated with hypnotic doses of pentobarbital $(50 \mathrm{mg} / \mathrm{kg})$, FAE $(400 \mathrm{mg} / \mathrm{kg})$ or QR $(4 \mathrm{mg} / \mathrm{kg})$ had significantly prolonged sleeping time (Fig. 1A) and shorter sleep latency (Fig. 1B) compared with vehicle mice. Mice treated with the sub-hypnotic doses of pentobarbital $(28 \mathrm{mg} / \mathrm{kg})$, FAE (400 or $800 \mathrm{mg} / \mathrm{kg})$ or QR $(4$ or $8 \mathrm{mg} / \mathrm{kg})$ had significantly more rapid rate of sleep onset that was dose dependent (Table I). As a positive control, DZ (2 mg/kg) also potentiated the hypnotic activity of pentobarbital in mice. FAE and QR administered alone did not induce sleep.

Synergic effects of FAE or QR and 5-HTP on sleep induced by pentobarbital. To investigate the association between the hypnotic activity of FAE or QR and the serotonergic system, mice were treated with FAE $(200 \mathrm{mg} / \mathrm{kg})$ or QR $(2 \mathrm{mg} / \mathrm{kg})$ for $60 \mathrm{~min}$ and with 5 -HTP $(2.5 \mathrm{mg} / \mathrm{kg})$ for $15 \mathrm{~min}$ prior to the administration of pentobarbital (50 mg/kg, ip). FAE (200 g/ $/ \mathrm{kg})$, QR $(2 \mathrm{mg} / \mathrm{kg})$ and 5 -HTP $(2.5 \mathrm{mg} / \mathrm{kg})$ administered individually did not affect sleeping time or sleep latency induced by hypnotic doses of pentobarbital (Fig. 2A and B). The rate of sleep onset induced by sub-hypnotic doses of pentobarbital 
Table I. Effect of FAE and QR on sleep onset of mice induced by sub-hypnotic dosage of pentobarbital $(28 \mathrm{mg} / \mathrm{kg})$.

\begin{tabular}{lccc}
\hline Groups & Total no. & $\begin{array}{c}\text { No. falling } \\
\text { asleep }\end{array}$ & $\begin{array}{c}\text { Sleep } \\
\text { onset, } \%\end{array}$ \\
\hline Vehicle & 15 & 0 & 0.0 \\
DZ, $2 \mathrm{mg} / \mathrm{kg}$ & 10 & 10 & 100.0 \\
FAE, & & & \\
$200 \mathrm{mg} / \mathrm{kg}$ & 15 & 1 & 6.7 \\
$400 \mathrm{mg} / \mathrm{kg}$ & 15 & 4 & $26.7^{\mathrm{a}}$ \\
$800 \mathrm{mg} / \mathrm{kg}$ & 15 & 7 & $46.7^{\mathrm{b}}$ \\
QR, & & & \\
$2 \mathrm{mg} / \mathrm{kg}$ & 15 & 2 & 13.3 \\
$4 \mathrm{mg} / \mathrm{kg}$ & 15 & 5 & $33.3^{\mathrm{a}}$ \\
$8 \mathrm{mg} / \mathrm{kg}$ & 15 & 8 & $53.3^{\mathrm{b}}$ \\
\hline
\end{tabular}

${ }^{\mathrm{a}} \mathrm{P}<0.05$ and ${ }^{\mathrm{b}} \mathrm{P}<0.01$ vs. vehicle $\left(\chi^{2}\right.$ test). FAE, extract of Flos albiziae; DZ, diazepam; QR, quercetin.

$\mathbf{A}$

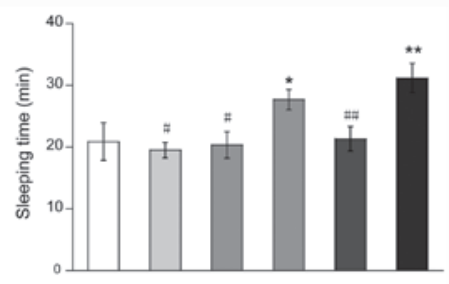

B

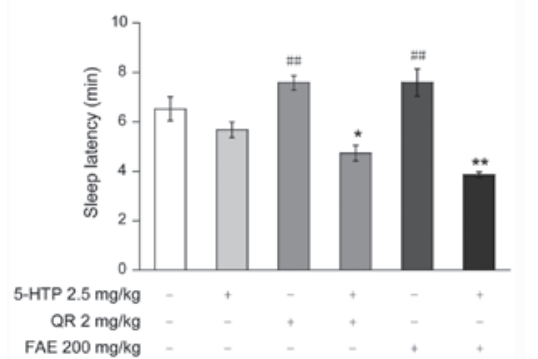

Figure 2. Synergic effects of the Flos albiziae extract (FAE) or quercetin (QR) and 5-hydroxytryptophan (5-HTP) on sleep induced by pentobarbital in mice $(\mathrm{n}=10)$. Mice were administered FAE $(200 \mathrm{mg} / \mathrm{kg})$ or QR $(2 \mathrm{mg} / \mathrm{kg})$ for $60 \mathrm{~min}$ and 5 -HTP $(2.5 \mathrm{mg} / \mathrm{kg})$ for $15 \mathrm{~min}$ prior to the injection of pentobarbital (50 mg/kg, intraperitoneal). (A) Sleeping times and (B) sleep latencies were measured. Data are mean \pm standard deviation. Significant differences of 5-HTP and QR or FAE-treated mice compared to the vehicle-treated mice $\left({ }^{*} \mathrm{P}<0.05\right.$ and $\left.^{* *} \mathrm{P}<0.01\right)$. Numbers represent significant differences of 5-HTP, $\mathrm{QR}$ or FAE-treated mice compared to the 5-HTP and QR or FAE-treated mice $\left({ }^{\#} \mathrm{P}<0.05\right.$ and $\left.{ }^{\# \#} \mathrm{P}<0.01\right)$.

was also unaffected (Table II). However, co-administration of FAE $(200 \mathrm{mg} / \mathrm{kg})$ or QR $(2 \mathrm{mg} / \mathrm{kg})$ and 5 -HTP $(2.5 \mathrm{mg} / \mathrm{kg})$ synergistically prolonged sleeping time (Fig. 2A) and shortened sleep latency significantly (Fig. 2B). Co-administration also significantly increased the rate of sleep onset (Table II) in mice treated with sub-hypnotic doses of pentobarbital.

Effect of FAE or QR on PCPA-induced insomnia in pentobarbital-treated mice. Treatment with PCPA $(300 \mathrm{mg} / \mathrm{kg}$, subcutaneous) has been shown to induce insomnia in mice. In accordance with previous studies $(13,14)$, mice pretreated with
Table II. Synergic effects of FAE or QR with 5-HTP on sleep onset of mice treated with sub-hypnotic dosage of pentobarbital $(28 \mathrm{mg} / \mathrm{kg})$.

\begin{tabular}{lccc}
\hline Groups & Total no. & $\begin{array}{c}\text { No. falling } \\
\text { asleep }\end{array}$ & $\begin{array}{c}\text { Sleep } \\
\text { onset, \% }\end{array}$ \\
\hline Vehicle & 15 & 0 & 0.0 \\
$5-\mathrm{HTP}, 2.5 \mathrm{mg} / \mathrm{kg}$ & 15 & 2 & $13.3^{\mathrm{a}}$ \\
FAE, $200 \mathrm{mg} / \mathrm{kg}$ & 15 & 1 & $6.7^{\mathrm{a}}$ \\
QR, $2 \mathrm{mg} / \mathrm{kg}$ & 15 & 2 & $13.3^{\mathrm{a}}$ \\
5-HTP, $2.5 \mathrm{mg} / \mathrm{kg}$ & 15 & 7 & $46.7^{\mathrm{b}}$ \\
+ FAE, $200 \mathrm{mg} / \mathrm{kg}$ & & & \\
5-HTP, $2.5 \mathrm{mg} / \mathrm{kg}$ & 15 & 8 & $53.3^{\mathrm{b}}$ \\
+ QR, $2 \mathrm{mg} / \mathrm{kg}$ & & & \\
\hline
\end{tabular}

${ }^{\mathrm{a}} \mathrm{P}<0.05$ vs. 5 -HTP $2.5 \mathrm{mg} / \mathrm{kg}+$ FAE $200 \mathrm{mg} / \mathrm{kg}$ or QR $2 \mathrm{mg} / \mathrm{kg}$ $\left(\chi^{2}\right.$ test). ${ }^{\mathrm{b}} \mathrm{P}<0.01$ vs. vehicle ( $\chi^{2}$ test). 5-HTP, 5-hydroxytryptophan; FAE, extract of Flos albiziae; QR, quercetin.

A

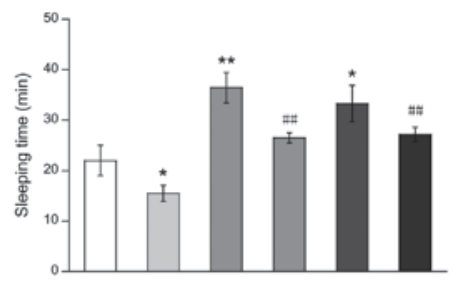

B

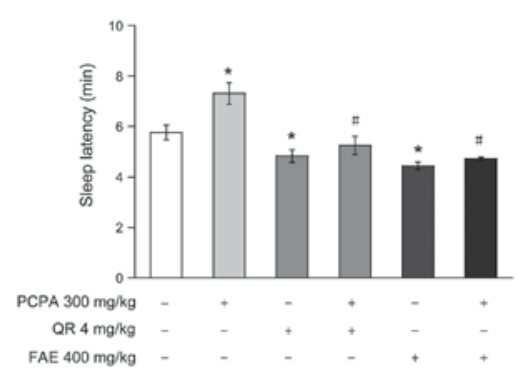

Figure 3. Effects of the Flos albiziae extract (FAE) or quercetin (QR) on $p$-chlorophenylalanine (PCPA)-induced insomnia in pentobarbital treated mice $(\mathrm{n}=10)$. Mice were pretreated with PCPA ( $300 \mathrm{mg} / \mathrm{kg}$, subcutaneous) for $24 \mathrm{~h}$ and $\mathrm{QR}(4 \mathrm{mg} / \mathrm{kg})$ or FAE $(400 \mathrm{mg} / \mathrm{kg})$ for $60 \mathrm{~min}$ prior to the injection of pentobarbital (50 mg/kg, intraperitoneal). (A) Sleeping times and (B) sleep latencies were measured. Data are mean \pm standard deviation. Significant differences of PCPA-, QR-, or FAE-treated mice compared to the vehicle-treated mice ( $\mathrm{P}<0.05$ and $\left.{ }^{* *} \mathrm{P}<0.01\right)$. Numbers represent significant differences of PCPA and QR or FAE-treated mice compared to the PCPA-treated mice $\left({ }^{\#} \mathrm{P}<0.05\right.$ and $\left.{ }^{\# \#} \mathrm{P}<0.01\right)$.

PCPA for $24 \mathrm{~h}$ prior to pentobarbital injection had significantly shortened sleeping time (Fig. 3A) and prolonged sleep latency (Fig. 3B). FAE (400 mg/kg) and QR (4 mg/kg) significantly attenuated insomnia induced by PCPA, which was reflected by increased sleep time (Fig. 3A) and decreased sleep latency (Fig. 3B).

\section{Discussion}

QR is a major flavonoid constituent of Albizia julibrissin Durazz flowers with purported medicinal effects. Data indicate that the active ingredients of FA, QR and isoquercetin, had 
hypnotic effects via potentiation of pentobarbital-induced sleep in ddY strain mice (5-6 weeks old) (2). FAE and QR (hydrolysis product of quercitrin) dose-dependently augmented the hypnotic activity of pentobarbital by prolonging sleeping time (Fig. 1A) and by increasing the rate of sleep onset (Fig. 1B; Table I) at 200-400 mg/kg FAE or 2-4 mg/kg QR. Higher doses of each ( 800 or $8 \mathrm{mg} / \mathrm{kg}$, respectively) did not change sleeping time and sleep latency (data not shown). The differences in the present data and those of previous studies may be explained by different animal strains, mouse ages, and drug doses and administration routes. By contrast, the data suggest double-direction regulation, specifically, inhibition and sedation at lower doses and excitation at higher doses. This effect has been documented for several compounds: Bakuchiol (16), rhubarb (17), naringenin (18) and Panax Notoginseng Saponins (19).

Serotonin not only has a role in inhibiting sleep and promoting wakefulness, it is also associated with the initiation and maintenance of sleep. Such complex effects of serotonin on the regulation of sleep and wakefulness are attributed to serotonin acting at different brain sites and 5-HT sub-type receptors associated with the control of the sleep-wake cycle (20). 5-HTP, the precursor of 5-HT, prolongs pentobarbital-induced sleeping time in a dose-dependent manner (14). Chronic administration of PCPA, which inhibits tryptophan hydroxylase, can inhibit $>95 \%$ of serotonin biosynthesis, resulting in complete insomnia or substantially reduced sleep (21). These insomnia effects can be reversed by subsequent treatment with 5-HTP, which may restore serotonin biosynthesis, thereby restoring sleep (22). This PCPA/5-HTP model suggests that 5-HT and 5-HTP are important for sleep-wake regulation. With this model, several studies suggest that CHM, such as tetrandrine, spinosin and ferulic acid $(13,14,23)$, may potentiate pentobarbital-induced sleep via the serotonergic system in mice.

FAE and QR had synergistic effects with 5-HTP by potentiating pentobarbital-induced sleep in mice, and acute treatment of PCPA $24 \mathrm{~h}$ prior to pentobarbital was observed to induce sleep suppression and this suppression can be inhibited by FA (Fig. 3). These results suggest that FAE and QR possess hypnotic effects, which may be mediated by the serotonergic system. Previous studies of FAE and QR have focused on their pharmacological effects, such as inhibition of cancer cell proliferation and induction of apoptosis, antidepressant effects, and antioxidant and hypolipidemic properties (6-9). The present study suggests that FAE and QR may also offer promise for the treatment of insomnia and diseases that may induce sleep disorders.

In conclusion, the present study is the first to reveal that the serotonergic system may be involved in hypnotic-sedative activity of FAE and QR. Further studies are required to elucidate the mechanisms behind these observations and to describe the associations between these drugs and different 5-HT receptor subtypes at different brain sites.

\section{Acknowledgements}

The present study was funded by the Technology Innovation Project of University Students in Zhejiang Province and Shaoxing City (grant nos. 2014R426026 and 2013124) and the Scientific Research Fund of Shaoxing University (grant no. 20125025) and the Science \& Technology Bureau of Shaoxing City (grant no. 2014B70052).

\section{References}

1. Yeung WF, Chung KF, Poon MM, Ho FY, Zhang SP, Zhang ZJ, Ziea ET and Wong VT: Chinese herbal medicine for insomnia: A systematic review of randomized controlled trials. Sleep Med Rev 16: 497-507, 2012

2. Kang TH, Jeong SJ, Kim NY, Higuchi R and Kim YC: Sedative activity of two flavonol glycosides isolated from the flowers of Albizzia julibrissin Durazz. J Ethnopharmacol 71: 321-323, 2000.

3. Bischoff SC: Quercetin: Potentials in the prevention and therapy of disease. Curr Opin Clin Nutr Metab Care 11: 733-740, 2008.

4. Xu R, Zhang Y, Ye X, Xue S, Shi J, Pan J and Chen Q: Inhibition effects and induction of apoptosis of flavonoids on the prostate cancer cell line PC-3 in vitro. Food Chem 138: 48-53, 2013.

5. Angst E, Park JL, Moro A, Lu QY, Lu X, Li G, King J, Chen M, Reber HA, Go VL, et al: The flavonoid quercetin inhibits pancreatic cancer growth in vitro and in vivo. Pancreas 42: 223-229, 2013

6. Anjaneyulu M, Chopra K and Kaur I: Antidepressant activity of quercetin, a bioflavonoid, in streptozotocin-induced diabetic mice. J Med Food 6: 391-395, 2003.

7. Tang Y, Gao C, Xing M, Li Y, Zhu L, Wang D, Yang X, Liu L and Yao P: Quercetin prevents ethanol-induced dyslipidemia and mitochondrial oxidative damage. Food Chem Toxicol 50: 1194-1200, 2012

8. Boots AW, Haenen GR and Bast A: Health effects of quercetin: From antioxidant to nutraceutical. Eur J Pharmacol 585: 325-337, 2008.

9. Chen X: Protective effects of quercetin on liver injury induced by ethanol. Pharmacogn Mag 6: 135-141, 2010.

10. Liu S, Hou W, Yao P, Li N, Zhang B, Hao L, Nüssler AK and Liu L: Heme oxygenase-1 mediates the protective role of quercetin against ethanol-induced rat hepatocytes oxidative damage. Toxicol In Vitro 26: 74-80, 2012.

11. Shi X, Jiang C,Zhao X, et al: Study on the efects of Albizia Julibrissin flower on cognitive function and plasma 5-HT, NE and DA in patients with depression: A randomized parallel controlled multicenter clinical trial. J Pract Tradit Chin Intern Med 27: 18-20, 2013.

12. Pujol JF, Buguet A, Froment JL, Jones B and Jouvet M: The central metabolism of serotonin in the cat during insomnia. A neurophysiological and biochemical study after administration of P-chlorophenylalanine or destruction of the Raphé system. Brain Res 29: 195-212, 1971.

13. Tu Y, Cheng SX, Sun HT, Ma TZ and Zhang S: Ferulic acid potentiates pentobarbital-induced sleep via the serotonergic system. Neurosci Lett 525: 95-99, 2012.

14. Zhao X, Cui XY, Chen BQ, Chu QP, Yao HY, Ku BS and Zhang YH: Tetrandrine, a bisbenzylisoquinoline alkaloid from Chinese herb Radix, augmented the hypnotic effect of pentobarbital through serotonergic system. Eur J Pharmacol 506: 101-105, 2004.

15. Jung JW, Cho JH, Ahn NY, Oh HR, Kim SY, Jang CG and Ryu JH: Effect of chronic Albizzia julibrissin treatment on 5-hydroxytryptamine1A receptors in rat brain. Pharmacol Biochem Behav 81: 205-210, 2005.

16. Mao H, Wang H, Ma S, Xu Y, Zhang H, Wang Y, Niu Z, Fan G, Zhu Y and Gao XM: Bidirectional regulation of bakuchiol, an estrogenic-like compound, on catecholamine secretion. Toxicol Appl Pharmacol 274: 180-189, 2014.

17. Qin Y, Wang JB, Kong WJ, Zhao YL, Yang HY, Dai CM, Fang F, Zhang L, Li BC, Jin C, et al: The diarrhoeogenic and antidiarrhoeal bidirectional effects of rhubarb and its potential mechanism. J Ethnopharmacol 133: 1096-1102, 2011.

18. Li HY, Liang B, Chen ZT, et al: Two-way effects on nasopharyngeal carcinoma CNE2 cells growth and mechanisms of different dose naringenin. Chin Pharm J 48: 2006-2012, 2013.

19. Wang $X Y$ and Zhang T: Research progress of the dual regulatory effects of Panax Notoginseng Saponins on angiogenesis. Chin Tradit Chin Med Pharm 28: 1818-1822, 2013.

20. Dugovic C: Role of serotonin in sleep mechanisms. Rev Neurol (Paris) 157: S16-S19, 2001.

21. Weitzman ED, Rapport MM, McGregor P and Jacoby J: Sleep patterns of the monkey and brain serotonin concentration: Effect of p-chlorophenylalanine. Science 160: 1361-1363, 1968.

22. Touret M, Sarda N, Gharib A, Geffard M and Jouvet M: The role of 5-hydroxytryptophan (5-HTP) in the regulation of the sleep/wake cycle in parachlorophenylalanine (p-CPA) pretreated rat: A multiple approach study. Exp Brain Res 86: 117-124, 1991.

23. Wang LE, Bai YJ, Shi XR, Cui XY, Cui SY, Zhang F, Zhang QY, Zhao YY and Zhang YH: Spinosin, a C-glycoside flavonoid from semen Zizhiphi Spinozae, potentiated pentobarbital-induced sleep via the serotonergic system. Pharmacol Biochem Behav 90: 399-403, 2008. 